\title{
Pacíficas consideraciones sobre la vida de los presbíteros
}

\author{
Víctor Codina, S.J., \\ Universidad Católica Boliviana, \\ Centro de Espiritualidad Ignaciana, \\ Cochabamba, Bolivia
}

El año sacerdotal, proclamado por Benedicto XVI con ocasión del $1500^{\circ}$ aniversario del Cura de Ars, San Juan María Vianney, nos ofrece una ocasión muy oportuna para reflexionar sobre el ministerio presbiteral. Sin entrar directamente en los temas dogmáticos en torno al ministerio, nos concentraremos en reflexionar sobre la vida de los presbíteros en su momento actual, su dimensión más existencial, sus dificultades y desafíos.

\section{La perspectiva del Vaticano II}

A diferencia del Vaticano I, que se centró en el ministerio papal, el Concilio Vaticano II trató especialmente del episcopado. Pero tanto los sacerdotes presentes en el aula conciliar como numerosos obispos creyeron que no se podía silenciar la importante misión del presbítero en la Iglesia y que era insuficiente dedicar a los presbíteros solamente un número del capítulo III de la Lumen gentium (LG 28). Esto justificó la elaboración del decreto Presbyterorum ordinis sobre el ministerio y vida de los presbíteros (PO), al que se añadió luego el decreto Optatam totius sobre la formación sacerdotal (OT).

No pretendemos comentar aquí el decreto Presbyterorum ordinis, sino únicamente destacar algunos elementos clave que se exponen para orientar la vida de los presbíteros.

Frente a la visión teológica del Concilio de Trento, que centraba el ministerio sacerdotal en la celebración del sacrificio eucarístico, el Vaticano II sitúa el ministerio presbiteral dentro de la tríada clásica: Palabra, Sacramentos y Gobierno pastoral de la comunidad, dando una cierta prioridad al ministerio de la Palabra (PO 4-6). 
Hay una cierta tensión entre la segregación del presbítero para consagrarse totalmente a su misión y su inserción en la comunidad humana, a cuya vida no puede ser extraño (PO 3).

También se mantiene la dialéctica entre el sentirse hermano y amigo del obispo y la necesaria obediencia (PO 7).

La actividad presbiteral puede ser múltiple: parroquial, interparroquial, de investigación y enseñanza, e incluso de trabajo manual en el mundo obrero (PO 8).

Es significativa la importancia que se da al presbiterio como una comunidad fraterna de mutua corresponsabilidad, de acogida y de ayuda, tanto material como espiritual, a los hermanos sacerdotes (PO 8).

A estas funciones más estructurales del ministerio presbiteral se añaden una serie de elementos que configuran la vida más personal del presbítero: su vocación a la perfección que se realiza a través del mismo ejercicio del ministerio, sobre todo a través de la caridad pastoral (PO 12-14), la aceptación libre y gozosa del celibato, aunque se reconoce que no es esencial al ministerio sacerdotal, como consta tanto de la historia de la Iglesia primitiva como de la praxis actual de la Iglesia del Oriente (PO 16), la aceptación voluntaria de la pobreza y el alejamiento de la ambición y del espíritu de lucro (PO 17), por más que el presbítero necesite de una justa remuneración y de fondos de previsión social (PO 20-21).

Se exhorta al presbítero a que viva una vida espiritual intensa, que dedique tiempo al estudio, sobre todo, de las ciencias sagradas (PO 19) y que confíe en el Señor ante las dificultades de la soledad y la aparente esterilidad apostólica (PO 22).

Aunque al principio el decreto reconoce que este ministerio ofrece hoy dificultades (PO 1), y al final afirma que será conveniente la acomodación del ministerio sacerdotal a las circunstancias del mundo de hoy (PO 22), el tono empleado en él es positivo, sereno, da por supuesto que se afirma algo conocido y aceptado por todos, sin que los obispos redactores del documento sospechen que en la Iglesia del posconcilio iba a surgir una problemática mucho más compleja y ardua para el ministerio presbiteral.

\section{De la doctrina conciliar a la realidad actual}

Hacer un estudio serio de la realidad del clero en la Iglesia de hoy exigiría un largo trabajo interdisciplinar que supera mi competencia y que no es lo que se pretende en un artículo que desea ser una simple nota o comentario al tema de la vida presbiteral.

Mi intención es más modesta, simplemente quisiera destacar algunos de los rasgos desafiantes de la realidad sacerdotal de hoy que, sin necesidad de estudios 
técnicos ni estadísticas, son ya claramente perceptibles para cualquier observador imparcial de la realidad. Nos limitamos a destacar algunas realidades de la vida presbiteral de la Iglesia occidental, europea y americana, más concretamente latinoamericana, dejando de lado la situación de las Iglesias de Asia, África y Oceanía, cuya problemática nos es menos conocida.

Como en el decreto conciliar, también nosotros nos referimos principalmente al clero diocesano, aunque muchas de las afirmaciones análogamente se pueden aplicar al clero religioso.

Sin ningún ánimo de exhaustividad, destaquemos algunas realidades que parecen indiscutibles y dejaremos para más adelante la reflexión sobre las causas y los desafíos. A más de 40 años después del Vaticano II, la situación del clero en la Iglesia ha cambiado profundamente.

Pero antes de señalar algunos de los problemas que hoy nos desafían quisiera expresar un testimonio de gratitud y admiración ante la vida ejemplar y evangélica de tantos miles de sacerdotes, viejos y jóvenes, que son un testimonio vivo de la presencia del Espíritu del Señor en la Iglesia de hoy, testimonio que en algunos casos ha llegado hasta el derramamiento de su sangre martirial. Valga esta afirmación previa para no producir la impresión de que en la vida de los presbíteros todo es conflicto y cuestionamiento. Pero hecha esta afirmación, no podemos dejar de ver la realidad tal cual es. A los gozos y esperanzas se añaden las tristezas y angustias de muchos presbíteros.

\subsection{Disminución del número de sacerdotes}

Esta es la primera observación que salta a la vista: hay menos presbíteros. hay menos vocaciones sacerdotales, la edad media del clero es alta, muchísimas parroquias no tienen sacerdotes, por todas partes se busca que un presbítero atienda a varias parroquias, se reestructuran las diócesis formando unidades supraparroquiales para atender pastoralmente en muchos lugares, los sacerdotes están sobrecargados de trabajo y multiplican sus actividades para responder a las demandas pastorales, se solicitan sacerdotes misioneros de otras diócesis para ayudar a las que carecen de sacerdotes suficientes, muchas celebraciones dominicales son dirigidas por laicos o religiosas, en ausencia de presbíteros (en Brasil, el 75\%, según el reporte de la Conferencia Episcopal), agentes pastorales laicos, algunos diáconos y algunas religiosas se encargan de tareas que antes eran casi exclusivas de los presbiteros: celebraciones de la Palabra, bautizos, bendición de matrimonios, exequias, catequesis, enseñanza de religión, pastoral social, visita a familias, cuidado de enfermos, pastoral penitenciaria, pastoral juvenil...

Un cambio cuantitativo de esta índole tiene consecuencias que no son meramente cuantitativas o numéricas, sino cualitativas. 
¿Cómo conciliar esta realidad innegable con las afirmaciones constantemente repetidas por el Vaticano II de que la eucaristía es fuente y culmen de la Iglesia (LG 11, SC 10, PO 5), quicio de la comunidad cristiana (PO 6)? ¿No estaremos propiciando una Iglesia de la Palabra, pero poco sacramental? Pero no podemos dejar de preguntarnos sobre el porqué de la disminución y falta de clero, por qué disminuyen las vocaciones al ministerio ordenado. ¿Es culpa únicamente del ambiente moderno poco religioso y agnóstico, de la desintegración familiar, de la poca generosidad de los jóvenes que rehúyen compromisos definitivos... o quizá esta disminución de vocaciones está más bien relacionada con la imagen de presbítero que ofrece la Iglesia institucional? Más adelante volveremos sobre esta cuestión.

\subsection{Aumentan los abandonos del ministerio}

Este tema se relaciona estrechamente con el anterior. Sin caer en catastrofismos, ciertamente llama la atención el gran número de presbíteros que han abandonado el ministerio en el posconcilio. Algunos autores afirman que ha sido una verdadera hemorragia en la Iglesia. Según algunos observadores eclesiásticos, esta es una de las causas que han provocado en algunos lugares reacciones conservadoras y anticonciliares, como si el Vaticano II fuera el causante de estas deserciones. Algunos episcopados, como el de Brasil en Aparecida, han pedido que muchos de estos sacerdotes, hoy padres de familia, se puedan reincorporar al ministerio, si ellos lo desean.

Muchísimos de estos casos sucedieron en el inmediato posconcilio, cuando se comenzaron a conceder dispensas del celibato, pero otros muchos casos han sucedido en años recientes y muchas veces de parte de presbíteros jóvenes, a veces recién ordenados.

Un hecho tan llamativo obliga a formular muchas interrogantes. ¿Por qué abandonan el ministerio personas muchas veces muy responsables y cualificadas? ¿Es simplemente porque no pueden vivir el celibato, como algunos piensan, o por algo más profundo que toca a la identidad ministerial del presbítero y al sentido de su misión en la Iglesia y el mundo de hoy?

\subsection{Insatisfacción por la formación recibida}

La formación recibida en los seminarios resulta para muchos sacerdotes insatisfactoria. Muchos cuestionan la misma estructura de los seminarios que tiene su origen en el Concilio de Trento. La uniformidad obligatoria para toda la Iglesia del sexenio filosófico-teológico, para muchos es hoy difícilmente aceptable. La occidentalización de la filosofía y de la misma teología es rechazada por muchos, hay un abismo entre lo que los seminaristas reciben en sus aulas y la práctica pastoral a la que se enfrentan al acabar los estudios. Las orientaciones 
positivas para su tiempo del decreto conciliar sobre la formación sacerdotal Optatam totius resultan inadecuadas e insuficientes para el mundo de hoy. Las acomodaciones que en algunos lugares se han hecho tampoco satisfacen, parecen más bien remiendos nuevos en un vestido viejo.

¿Tiene que mantenerse la actual estructura de los seminarios menores, e incluso la de los mismos seminarios mayores, como algo obligatorio y universal para todos los lugares de la Iglesia? ¿Es conveniente que por largo tiempo los seminaristas vivan alejados de sus familias y de la realidad circundante (también de la mujer), por más que los seminaristas tengan prácticas pastorales semanales o en vacaciones? La misma idea tridentina de "seminario", es decir semillero, con riesgo de ser un invernadero, ¿se puede mantener como la única manera de formación hoy, obligatoria para todos los candidatos al ministerio ordenado, en un mundo que vive un gran proceso de transformación, en una sociedad globalizada, donde los medios de comunicación nos avasallan y el mundo digital de Internet y los celulares nos conecta con toda la humanidad? ¿No sería más normal, y a la larga mejor, que los jóvenes se formaran en parroquias o en comunidades más reducidas, en cercanía a los ambientes que luego han de frecuentar?

Más aún, ¿cómo pensar en la formación de aspirantes al sacerdocio que ya no sean adolescentes, sino personas formadas y con estudios universitarios o incluso profesionales? ¿Cómo formar a los candidatos al sacerdocio que provienen de culturas originarias, indígenas o afroamericanas? ¿No se debería dejar a las iglesias locales una gran libertad a la hora de estructurar la formación de sus futuros sacerdotes? ¿Se podrá mantener por más tiempo esta uniformidad vertical y universal que es más propia de la época de la cristiandad medieval que del mundo moderno y posmoderno de hoy?

\subsection{Emergencia del problema económico}

Es evidente que el trabajador, también el presbítero, merece su salario. Sería deseable que la comunidad cristiana subvencionase al clero que está a su servicio. O que el obispo remunerase a sus colaboradores. De todo esto habla el decreto Presbyterorum ordinis.

Pero todo esto, en la práctica, sobre todo en América Latina, es sumamente precario y dificultoso. En realidad, muchos presbíteros sobreviven casi únicamente de los estipendios que reciben por los sacramentos (bautizos, confirmaciones, matrimonios) y más concretamente de las misas que celebran, sobre todo las de difuntos y las de las fiestas patronales. Dejando de lado la cuestión de si no mantenemos al pueblo en un imaginario del purgatorio que no responde ya a la escatología moderna, la frecuencia de eucaristías tiene el riesgo de caer en el vicio de los curas "altaristas" que criticaba Lutero y que el mismo Trento quiso corregir. La prioridad que el Vaticano II da al ministerio de la Palabra en 
la práctica queda cuestionada por una mayor incidencia en lo sacramental, que es económicamente mucho más rentable. De ahí nace también la búsqueda de parroquias urbanas y sobre todo de las de los barrios más acomodados. ¿Dónde queda la insistencia de una nueva evangelización, de anunciar el kerigma, de iniciar a la experiencia espiritual del encuentro con el Señor para formar auténticos discípulos misioneros, si gran parte de la pastoral queda reducida a la celebración (o a veces mera "administración") de los sacramentos?

¿Cómo pensar de cara al futuro el ministerio presbiteral de modo que su economía no dependa casi exclusivamente de la práctica sacramental? ¿No se debería buscar alguna otra forma de ganarse la vida, no estrictamente ligada al mundo de lo sagrado? En una sociedad cada vez más secular, ¿no se podría pensar en ejercer otras profesiones que, al mismo tiempo que provean del sustento económico, abran a perspectivas más misioneras, como en su tiempo hicieron los sacerdotes obreros y hoy algunos presbíteros hacen en el ejercicio del magisterio? Los 30 años de carpintero de Jesús de Nazaret, el trabajo artesanal de Pablo, que construía carpas, ¿no pueden decirnos algo al respecto?

\subsection{Escándalos sexuales}

Ciertamente, no es la primera vez que en la historia de la Iglesia se producen escándalos sexuales. No en vano los Padres de la Iglesia la llamaban "casta meretrix", casta prostituta. Siempre ha habido historias desedificantes tanto en la cabeza de la Iglesia como en el seno de las iglesias locales: infidelidades al celibato prometido, curas mujeriegos con hijos que pasaban por ser sus sobrinos, etc. La naturaleza humana, también la sacerdotal, es frágil y está sometida a todo tipo de tentaciones, también a las de la carne. No debemos maravillarnos ni rasgarnos hipócritamente las vestiduras. El que esté libre de pecado que lance la primera piedra...

Pero los casos de pedofilia que se han registrado últimamente, y que los medios de comunicación se han encargado de difundir y de magnificar con gran sensacionalismo como si fuesen algo común y ordinario en la vida sacerdotal, son ciertamente algo nuevo, como también lo son las graves consecuencias económicas de algunas diócesis y de algunas provincias religiosas que han tenido que pagar sumas millonarias para compensar a las víctimas de los abusos sexuales cometidos por sacerdotes, a veces hace muchos años. Algunas diócesis se han declarado en quiebra. Tampoco sabemos si todas estas acusaciones son ciertas o han sido un montaje de gente inescrupulosa y de abogados especializados en estos temas.

Pero la realidad, por dolorosa que sea, está presente. No nos corresponde aquí investigar las causas psicológicas que han podido derivar en estos abusos, ni juzgar cómo se han manejado estos casos por parte de las diócesis. Pero lo que 
no nos parece correcto es la afirmación de instancias oficiales de la Iglesia que aseveran que estos excesos no tienen nada que ver con el tema del celibato. Los autores espirituales y teólogos antiguos eran más lúcidos al afirmar, partiendo de lo que habían experimentado en algunas comunidades muy cerradas, que muchas veces la edad suple al sexo (aetas suplet sexum). Los psicólogos y sociólogos lo pueden confirmar con sus estudios sobre comportamientos sexuales en cuarteles y cárceles.

No querer relacionar estos abusos con el tema del celibato obligatorio para los sacerdotes de la Iglesia latina es cerrar los ojos a una cuestión evidente. El sexo parece ser un tema tabú en la Iglesia. ¿Por qué fue vetado por Juan XXIII al tratar el tema del celibato en el Vaticano II? ¿Por qué, sistemáticamente, no se quiere hablar de ello en sínodos y asambleas generales del episcopado, como si no fuera un problema real en muchas diócesis y en muchas culturas donde un hombre célibe no es respetado hasta que contraiga matrimonio? ¿Por qué en recientes sínodos de la Iglesia no se ha querido considerar la posibilidad de ordenar como presbíteros a varones casados, "viri probati", que muchos episcopados veían como una solución ante la falta de clero? ¿Por qué tanta suspicacia ante las numerosas ordenaciones de diáconos casados (por ejemplo, en Chiapas, México) si no es por el miedo a que pueda ser un primer paso para tener sacerdotes casados?

Aunque muchos sacerdotes asumen libremente y con gozo el celibato sacerdotal, para otros el celibato asumido en su ordenación constituye un problema, pues ellos desearían poder ejercer el ministerio presbiteral sin el celibato obligatorio, así como otros muchos jóvenes seguramente se animarían a servir a la Iglesia como presbíteros si esta vocación no llevase consigo aneja la promesa del celibato. Por otra parte, si el celibato no se vive en el seno de una comunidad presbiteral (o religiosa), a la larga es muy difícil de sobrellevar, pues la soledad no es buena consejera. ¿Se prepara a los seminaristas para poder vivir luego con otros sacerdotes en comunidad?

Por último, queremos señalar que el tema del celibato no tiene la misma significación para el clero diocesano que para la vida religiosa, pues mientras el celibato forma parte esencial de la consagración religiosa (lo cual agrava todavía más los abusos sexuales de algunos de sus miembros), no es algo esencial al presbiterado, como lo demuestra la praxis de la Iglesia primitiva y de la Iglesia católica oriental, sino que es una decisión de la Iglesia latina, que por venerable que sea, no tiene que ser necesariamente inmutable.

\subsection{Resurgir del clericalismo}

El esquema que había elaborado la comisión romana encargada de preparar la constitución sobre la Iglesia para el Vaticano II fue rechazado por los obispos 
llegados de todo el mundo con la acusación de que era un esquema clerical. Por esto, la constitución sobre la Iglesia Lumen gentium antepuso al capítulo de la jerarquía el del Pueblo de Dios, verdadera revolución eclesiológica que todavía muchos sectores eclesiales no han asimilado.

Así, aunque el lenguaje oficial de la Iglesia siempre pondera que somos una comunidad y los documentos recientes hablan de la parroquia como comunidad de comunidades, muchos laicos se quejan de que los presbíteros, en especial los párrocos, se consideran los dueños de la Iglesia. Los laicos, en especial las mujeres y también las religiosas, lamentan el ser continuamente discriminadas en la marcha de la Iglesia, acusan con frecuencia al clero de ser prepotente y machista, de mantener una división rígida entre clero y fieles, entre el clero que enseña, manda y celebra, y los que tienen que callar, obedecer y aprender.

Todos los documentos eclesiales en los que se dice que los presbíteros han de considerar a los laicos como hermanos, y escucharles (PO 9, LG 37), parecen papel mojado. Los presbíteros, desde su vida en el seminario, son imbuidos de su dignidad "sagrada", de que forman parte de la jerarquía que tiene unos poderes sagrados que nadie más posee. El mismo nombre de "jerarquía", poder sagrado, parece confirmar esta postura de superioridad del clero sobre los laicos, cuando en realidad la palabra "jerarquía" no es bíblica, pertenece al lenguaje místico teológico y neoplatónico del Pseudo Dionisio Areopagita. Los nombres bíblicos son más modestos y funcionales: discípulo, apóstol, anciano, vigilante, servidor.

Pero yendo más al fondo, muchos presbíteros reproducen inconscientemente frente a sus fieles la relación patrón-siervo que ellos mismos viven frecuentemente frente a sus obispos. Se repite el esquema piramidal de la Iglesia de la cristiandad frente al esquema circular y comunitario de la Iglesia primitiva y del Vaticano II. Los expertos en la historia de la liturgia han constatado que el gesto del sacerdote de arrodillarse ante su obispo para prometerle obediencia y fidelidad, después de su ordenación sacerdotal, reproduce el esquema feudal del siervo que promete fidelidad a su señor a cambio de su protección.

Estamos muy lejos de la actitud del buen pastor que conoce y guía a sus ovejas, de Jesús que no llama a sus discípulos siervos, sino amigos, de la apertura al diálogo que el Vaticano II propicia.

Podemos preguntarnos: ¿qué esquema de Iglesia subyace en estas actitudes clericales y prepotentes de muchos - no todos - sacerdotes frente a sus fieles laicos y, sobre todo, frente a las mujeres? ¿Qué teología del ministerio han asimilado durante su formación?

Antes de acabar esta sección, digamos que la lista de problemas e interrogantes que presenta hoy el ministerio presbiteral podría, sin duda, alargarse todavía más. Basten los arriba citados para tomar conciencia de que estamos ante 
la punta de un iceberg muy profundo, no simplemente ante un hecho meramente coyuntural y pasajero.

\section{Desafíos para el mundo de hoy}

\subsection{Discernir los signos de los tiempos}

Indudablemente, ante estos problemas detectados de la vida de los presbíteros, cabe una respuesta moral y espiritual: que estos sean fieles a sus promesas, que sean hombres de oración, que frecuenten el sacramento de la reconciliación, que sigan las normas ascéticas que la tradición ha demostrado ser útiles, que profundicen en la Palabra y vivan conforme a lo que celebran, que dediquen tiempo al estudio, que sean sensibles a los pobres, que imiten los ejemplos de tantos santos sacerdotes que han existido a lo largo de la historia de la Iglesia, entre los cuales, sin duda, destaca el Santo Cura de Ars.

Todo esto, por bueno y necesario que sea, ¿es suficiente para responder a los desafíos de hoy? No basta exigir a los sacerdotes orden, disciplina, obediencia, fidelidad y piedad. Es necesario algo más.

Hay que escuchar un clamor a veces sordo, a veces a gritos, que surge de muchas vidas de sacerdotes que desearían un estilo presbiteral diferente en una Iglesia diferente. A través de este clamor podemos percibir un auténtico signo de los tiempos, la voz del Espíritu que se manifiesta en medio de ambigüedades y tal vez errores, pero que debe ser discernida y no puede ser extinguida ni apagada.

Formulado de otro modo, la vida de los presbíteros constituye un verdadero lugar teológico que sub contrario interpela a la Iglesia y debe ser tenido en cuenta. ¿Qué es lo que los presbíteros de hoy, a través de su disminución numérica, de sus escándalos, de su prepotencia clerical, de su insatisfacción existencial, de su perplejidad ante la disminución de vocaciones, de sus problemas económicos y afectivos no resueltos... nos están diciendo a los demás miembros de la Iglesia?

Estamos, ciertamente, ante un cambio de época, ante un fuerte tsunami que sacude y barre muchas convicciones y estructuras sociales, políticas, económicas, científicas, culturales, religiosas y también eclesiales. Nada en el futuro será igual al pasado.

En estos momentos de profundos cambios, es necesario recuperar la identidad propia, en este caso la del presbítero, para que en esta convulsión epocal no perdamos lo que es esencial ni, por el contrario, identifiquemos algo que ha sido solamente coyuntural de otras épocas como definitivo e inmutable.

Es cierto que la Iglesia, como cualquier otra institución humana, necesita dirigentes, pues no puede ser una comunidad acéfala o ácrata. Pero en la Iglesia los 
dirigentes líderes tienen un carácter especial: son un carisma o don del Espíritu para el bien de la comunidad, son ministerios o servicios para la edificación de la Iglesia; por ello, necesitan de una ordenación eclesial-sacramental, significada con la imposición de las manos y la invocación del don del Espíritu.

Esta orientación al servicio de la comunidad es decisiva para comprender la identidad del presbiterado y de los demás ministerios ordenados. Esto significa que la comunidad tiene el derecho a tener los ministros necesarios para poder vivir plenamente su vida eclesial de bautizados, como Pueblo de Dios.

Ahora bien, la eucaristía es esencial y básica para la vida de la Iglesia, porque en ella participamos comunitaria y sacramentalmente del evento fundacional de la Iglesia que es el misterio pascual de Jesús muerto y resucitado. Es algo adquirido por la tradición que siempre ha afirmado que el que preside la comunidad eclesial debe también presidir la eucaristía, porque "la Iglesia hace la eucaristía y la eucaristía hace la Iglesia". La doctrina del Vaticano II ha vuelto a recordarlo reafirmando que la eucaristía es fuente y cumbre de la vida eclesial. En lenguaje jurídico podríamos decir que el derecho de una comunidad a poder participar de la eucaristía es un derecho divino, que pasa por delante de todas las leyes eclesiásticas, por venerables que sean.

\subsection{De un ministerio presbiteral único y uniforme a un pluralismo de estilos y formas}

Si todo lo anterior es cierto, podemos deducir que si la ley del celibato obligatorio para la Iglesia latina, venerable y sin duda con muchos valores, dificulta de hecho el que muchas comunidades puedan celebrar la eucaristía de modo ordinario, debe ser revisada. Rezar por las vocaciones sacerdotales al Señor de la mies es algo que siempre debemos hacer, pero no podemos poner condiciones a la gracia y al Espíritu, excluyendo del ministerio a las mujeres (ique son la mitad de la humanidad!) y a todos los varones casados (que son la mayoría de los varones).

Esta afirmación, que a muchos tal vez pueda sorprender, es teológicamente correcta y tiene su fundamento en la misma Escritura, que atestigua que en los orígenes de la Iglesia no existía una forma única de ministerio, sino múltiple (apóstoles, profetas, doctores, discípulas y apóstolas), y sí existía una pluralidad de estilos de vida que incluían tanto el matrimonio como la virginidad o el celibato.

La comunidad primitiva se caracterizó por una gran creatividad en el momento de establecer los ministerios necesarios, que hacia el siglo II se estabilizaron en la tríada obispo, presbítero y diácono.

Recuperar la variedad de ministerios y de estilos de vida en la forma de ejercerlos no es ninguna novedad, sino una vuelta a los orígenes más primitivos de la Iglesia. 
Tomando esto en cuenta deberíamos caminar hacia la posibilidad de diversas formas de ejercer y vivir el presbiterado: presbíteros célibes y presbíteros casados (jviri probati!), lo cual también debería abrir la puerta, hoy cerrada, para ministerios femeninos, dados los cambios sociales y culturales del mundo de hoy, en el cual la mujer accede a lugares que en la antiguiedad eran impensables.

También se deduce de aquí que las formas diferentes de vivir el presbiterado en el clero diocesano y en la vida religiosa, lejos de ser una extraña complicación canónica, son una riqueza eclesial y una forma de expresar el pluralismo que originalmente hubo dentro del mismo presbiterado, un ministerio más local y estable, a cargo de una comunidad, y un ministerio más itinerante y misionero, más paulino, abierto a las nuevas fronteras. En este sentido, la actual parroquialización de la vida religiosa puede ser un engañoso y empobrecedor intento de asimilar todo el clero al diocesano, perdiendo la riqueza carismática de los orígenes de cada comunidad religiosa.

Esta pluralidad de formas de vivir el ministerio presbiteral comporta una variedad de estilos de formación al ministerio, según edades (igénero!), culturas y estilos de vida sacerdotal. Esto implica que la categoría del seminario conciliar obligatorio para todos los aspirantes al sacerdocio debería revisarse y cuestionarse profundamente. Igualmente los contenidos humanísticos y teológicos requeridos, que deberían variar según culturas, destinos futuros, edades, lugares, etc. El actual sexenio filosófico-teológico no es ningún dogma inmutable, sino que debe ser revisado y adaptado a cada contexto y según la orientación futura del presbítero.

\subsection{De un ministerio presbiteral segregado a un ministerio inserto e integrado}

Hemos constatado las dificultades que nacen de un presbiterado que se siente por encima de la comunidad, superior a ella, segregado durante su formación y en su vida cotidiana, con mentalidad de ser el poseedor de poderes sagrados jerárquicos que lo distancian del resto de los laicos y en especial de las mujeres.

Detrás de esta mentalidad, típica de la Iglesia de la cristiandad, se esconde un problema teológico y cultural. En el fondo se mantiene una visión dualista de la realidad, escindida entre lo sagrado y lo profano, asignando al sacerdote lo sagrado (jel mismo nombre de sacerdote es significativo!) y relegando al laico a la esfera de lo profano.

Esta visión es más propia del Antiguo Testamento que del Nuevo Testamento, es más helénica que cristiana, pues Jesús rompió los esquemas tradicionales del sacerdocio de las religiones y, con su encarnación, su vida, su muerte y su resurrección, abolió la diferencia entre lo sagrado y lo profano, y abrió el camino para otra visión del sacerdocio cristiano. Él es el único mediador, un sacerdote 
fiel y compasivo ( $\mathrm{Hb} 2,17-18$ ), igual en todo a nosotros menos en el pecado ( $\mathrm{Hb} \mathrm{4,} \mathrm{14-15).}$

De ahí que toda la mentalidad segregacionista acerca del sacerdote en su vida y formación, la actitud clerical de superioridad sobre la comunidad, tiene que ser radicalmente corregida y superada.

Hay que abrir espacio hacia un ministerio cercano, compasivo, con entrañas de misericordia hacia todos los que sufren, verdadero buen pastor que da la vida por sus ovejas, dialogante e inserto en la comunidad, no por encima de ella, cuya misión es hacer que la comunidad sea fiel al proyecto de Jesús: crear un mundo filial y fraterno, donde los pobres, lejos de ser excluidos, ocupen un lugar privilegiado. La vida y la espiritualidad del presbítero no puede ser una imitación de la espiritualidad monástica, sino que debe partir y vivir de su realidad pastoral, viviendo la caridad pastoral como el Vaticano II propone.

Desde esta mentalidad hay que revisar la cuestión económica del clero, su trabajo, abrirse a trabajos y profesiones seculares para recibir su remuneración y no depender exclusivamente de los estipendios con motivo de los sacramentos.

También desde esta nueva visión, que no relega al clero en lo sacral y al laico en lo secular, hay que repensar los ministerios laicales que ni son un atentado contra la vocación del presbítero ni una competencia desleal, sino un ejercicio fiel del sacerdocio del Pueblo de Dios, de los bautizados, una colaboración activa y participativa en la vida de la comunidad eclesial.

Si Trento definió el sacerdocio en relación al sacrificio eucarístico y el Vaticano II amplió su visión a la Palabra y al cuidado pastoral de la comunidad, desde América Latina, la misión sacerdotal, asumiendo la visión del Vaticano II, se abre al horizonte del Reino, a la justicia y a los pobres, a la promoción y defensa de la dignidad humana, a la defensa de la vida amenazada, a comunicar al pueblo la plenitud y abundancia de vida que Jesús nos trajo (Jn 10, 10).

\section{Epílogo narrativo}

Tal vez el conocido cuento de Andersen El traje nuevo del rey puede resumir de forma narrativa lo que hemos querido expresar en estas páginas sobre la situación de los presbíteros.

Cuentan que un sastre famoso, pero que en realidad era un auténtico farsante, un mentiroso y confabulador, se ofreció a un rey oriental para hacerle un traje maravilloso de tisú de oro. El rey, que quería lucir elegante en una fiesta de su país, aceptó gustoso la invitación del famoso sastre, sin caer en la cuenta de que se trataba de un puro engaño y que no existía el tal vestido prometido.

Después de varios días de trabajo y de pruebas, el sastre dio por terminada su labor, y el rey decidió estrenar su nuevo traje el día de la fiesta. Así, salió 
del palacio a la calle completamente desnudo, enseñando sus vergüenzas, pero nadie del pueblo se atrevió a decir nada, porque todos habían oído que era un sastre muy famoso el que había hecho un traje maravilloso de tisú de oro al rey y temían ofender al monarca y perder sus favores. A mitad del recorrido, un niño se atrevió a alzar la voz y gritó, ante el asombro de todos: ¡el rey está desnudo!

Quizás también en la Iglesia necesitamos que algunas voces se alcen y digan sin miedo que hay realidades y situaciones que no pueden seguir igual que antes. Seguramente, una de las realidades que no puede hoy continuar igual que siempre es la de la vida de los presbíteros. 